UNCLASSIFIED

RECORDS ADMINISTRATION

R0138646

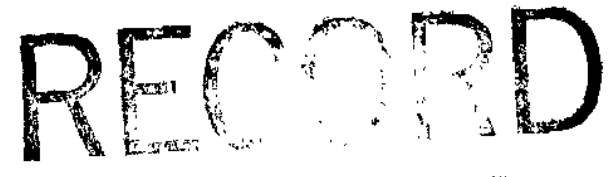

DP - 79

Instrumentation

40

\title{
A TESTER FOR PILE FLUX MONITORS
}

by

L. Cathey

Instrument Development Division

September 1954

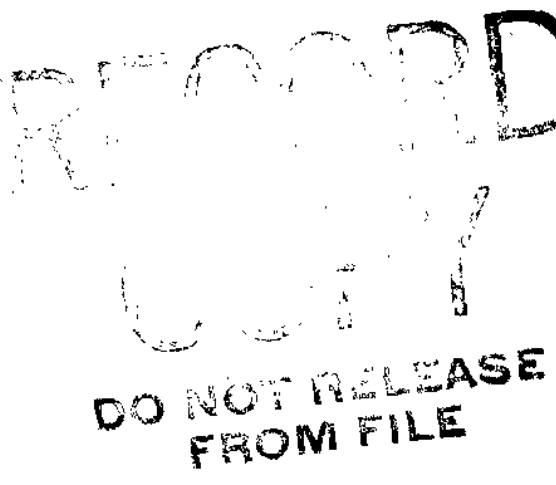

E. I. du Pont de Nemours \& Co.

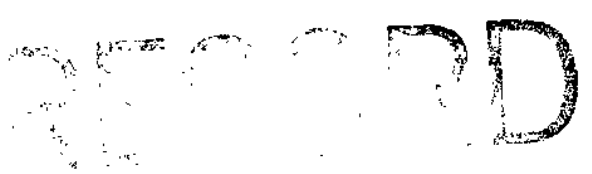

Do Fout rite

Explosives Department - Atomic Energy Division Technical Division - Savannah River Laboratory 
A TESTER FOR PILE FLUX MONITORS

by

L. Cathey

Instrument Development Division

September 1954

E. I. du Pont de Nemours \& Co. Explosives Department - Atomic Energy Division Technical D1vision - Savannah River Laboratory

Contract AT (07-2)-1 with the United States Atomic Energy Commission 
INTERNAL DISTRIBUTION

Copy No.

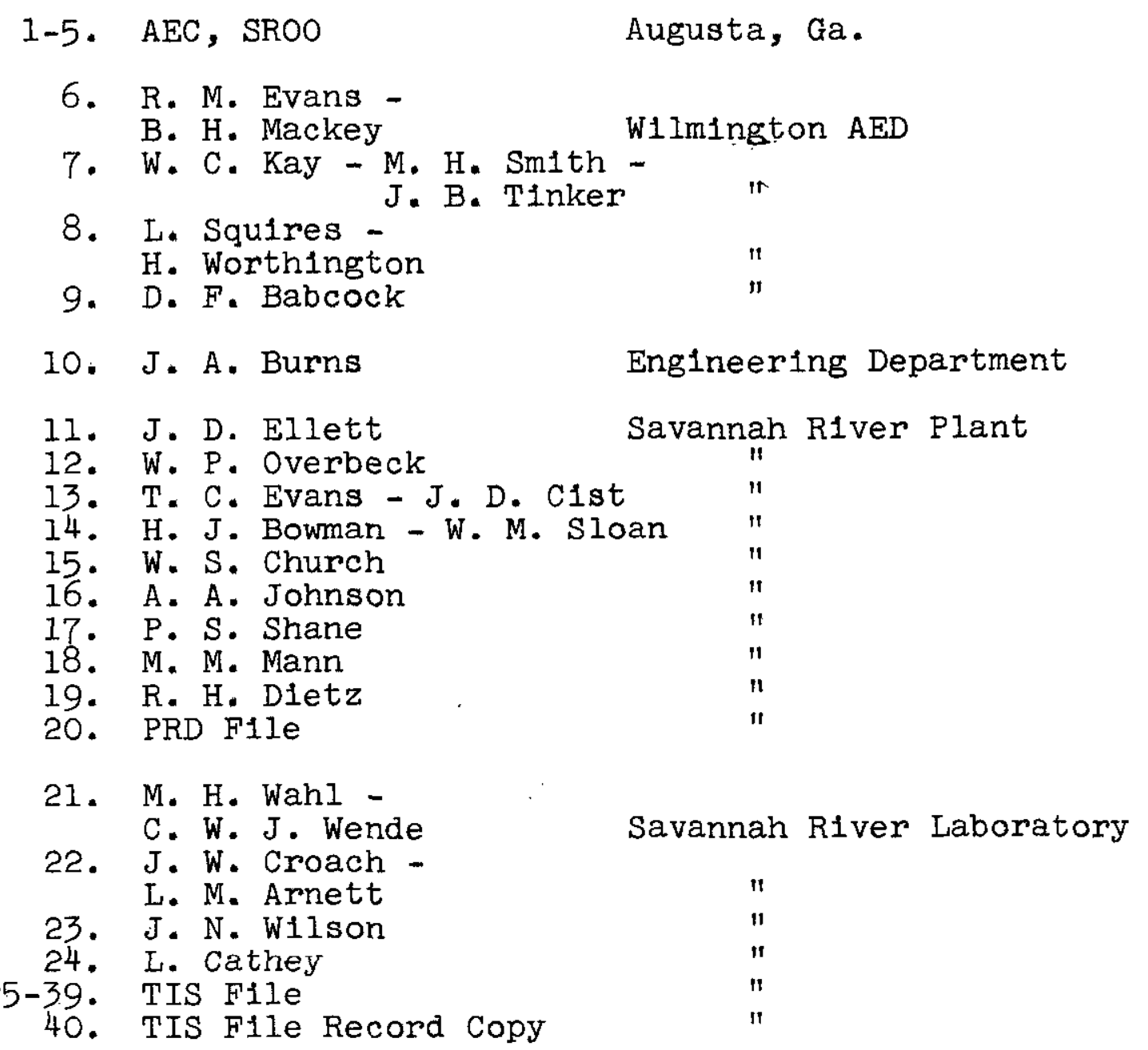




\section{EXTERNAL DISTRIBUTION}

Copy No.

41. Argonne Cancer Research Hospital

42-45. Argonne National Laboratory

46-50. Armed Services Technical Information Agency, Dayton

51-52. Army Chemical Center

53. Army Medical Research Laboratory

54. Army Medical Service Graduate School

55. Atomic Energy. Commission, Patent Branch

56-58. Atomic Energy Commission, Technical Library

59. Atomic Energy of Canada Limited

60. Australian Atomic Energy Commission

61. Battelle Memorial Institute

62. Belgium, Centre diEtudes pour les Applications de l'Energie Nucleaire

63-65. Belgium, Union Miniere du Haut Katanga

66-69. Brookhaven National Laboratory

70. Bureau of Ships (Code 490)

71-72. Canadian Joint Staff (Taber)

73. Carbide and Carbon Chemicals Company, C-31 Plant

74-75. Carbide and Carbon Chemicals Company, K-25 Plant

76-79. Carbide and Carbon Chemicals Company, ORNL

80-81. Carnegie Institute of Technology

82-85. Chalk River Project, Canada

86. Chicago Patent Group

87. Columbia University (Dr. Failla)

88-89. Columbia University (Dr. Hassialis)

90. Commonwealth X-Ray \& Radium Laboratory

91-92. Consolidated Vultee Aircraft Corporation

93. Department of Army, Office of Ordnance Research

94. Department of Navy, Code.811

95-96. Division of Raw Materials, Denver

97. Division of Raw Materials, Ishpeming

98. Division of Raw Materials, Salt Lake City

99-100. Dow Chemical Company, Midland

101. Dow Chemical Company, Rocky Flats

102-103. Eldorado Mining and Refining Limited

104. Frankford Arsenal

105-106. General Electric Company (ANPP)

107-108. General Electric Company, Richland

109-111. Goodyear Atomic Corporation

112. Harshaw Chemical Corporation

113-114. Iowa State College

115. Italy, Centro Italian Stud1 Experienze

116. Ka1ser Engineers

117. Kirtland Air Force Base

118-119. Knolls Atomic Power Laboratory

120-121. Los Alamos Scientific Laboratory 
EXTERNAL DISTRIBUTION (Continued)

Copy No.

122. Mallinckrodt Chemlcal Works

123. Massachusetts Institute of Technology (Dr. Kaufmann)

124. Mound Laboratory

125. National Advisory Committee for Aeronautics, Cleveland

126. National Bureau of Standards, Atomic Energy Project

127. National Bureau of Standards, Library

128. National Lead Company of Ohio

129. National Research Corporation

130-132. Nat1onal Research Counc11, Canada

133. Naval Medical Research Institute

134-136. Naval Research Laboratory

137. New Brunswick Laboratory

138. Newport News Shipbuilding and Dry Dock Company

139. New York Operations Office

140. North American Aviation, Inc.

141. Nuclear Development Assoclates, Inc.

142. Oak Ridge Institute of Nuclear Studies

143-146. Phillips Petroleum Company

147. Princeton University

148-150. Pub11c Health Service

151. RAND Corporation

152. Sandia Corporation

153-237. Technical Information Service, Oak Ridge

238. The Surgeon General

239. Tokyo University

240. United Aircraft Corporation

241-255. United Kingdom Sc1entific M1ssion

256-257. U.S. Geological Survey (Mr. Butler)

258-259. U.S. Naval Rad1ological Defense Laboratory

260. UCLA Medical Research Laboratory

$261-262$

University of California Radiation Laboratory

263-265. University of California Radiation Laboratory, Livermore Site

266. University of Chicago, A.F. Radiation Laboratory

267-268. University of Michigan (Dr. Gomberg)

269-270. University of Rochester, Atomic Energy Project

271. Un1versity of Utah

272. University of Washington, Applied Fisheries Laboratory

273. Vitro Corporation of America

274. Walter Kidde Nuclear Laboratories, Inc.

275. Watertown Arsenal

276-279. Westinghouse Electric Corporation

280. Yale University (Dr. Wadey) 
$D P-79$

Page 5

INSTRUMENTATION

\section{ABSTRACT}

A mechanoelectrical instrument is described which is used to calibrate logarithmic micromicroammeters and associated period measuring systems. 
Figure I Circuit Diagram . . . . . . . . . . 12 Figure 2 Photograph of the Pane1.......... 13 Figure 3 Photograph of Top of Chassis ....... 14 Figure 4 Curve of Exponential Generator ...... I5 
DP -79

Page 7

A TESTER FOR PILE FLUX MONITORS

INTRODUCTION

For the safe operation of a pile it is necessary to know the neutron flux level and its rate of change. The instruments for obtaining this information at the Savannah R1ver Plant contain a logarithmic micromicroammeter and a period computer to determine the rate of change of the neutron flux by measuring the current from an ion chamber.

An instrument to calibrate the micromicroammeter and pile period computer was necessary. Th1s report covers the development of such a device.

\section{SUMMARY}

A tester was developed that satisfactorliy simulates the currents produced by ion chambers in pile service.
The tester can generate currents in the range 10-13 to 10-4 amperes and can supply the following signals:

1. A current that increases or decreases exponentially with time over a range of two decades. The period may be chosen between 1.5 and 180 seconds.

2. Any steady current in the range of the tester.

3. Stepwise changes in current that are adjustable in magnitude up to 9 per cent of the current.

The generation of an exponentially varying signal is achieved by rotating at constant speed three ganged hel1pots that are connected in a network with flxed resistances. The circuit is so designed that the output voltage from the network approximates an exponential function of the angle of rotation of the helipots.

Four units are in use at the Savannah River Plant. 


\section{DISCUSSION}

The safe operation of a plle is very dependent upon knowledge of the neutron flux level and rate of change of this flux level. Since the growth or decay of the neutron flux in a pile approximates an exponential curve, it is convenient to compute the coefficient of the exponential as the inverse period of growth or decay of the neutron flux. The period is computed by taking the derivative with respect to time of the logarithm of the pile flux.

Monitoring of the pile flux is done by neutronsensitive ion chambers. The logarithmic and differentiation computations on the 1on chamber currents are both done electronically. The aging of vacuum tubes will vary the calibration of these electronic computers, so some means of standardization is necessary.

DESCRIPTION

The tester consists of four main units on one chassis: power supply, two transient generators, and an attenuator. The circuit diagram is shown in Figure 1.

The power supply, which is regulated by a glow tube, dellvers $105 \pm 3$ volts direct current. The current is well filtered to reduce the 60 cycle ripple content. The transformer and choke are mounted as far as possible from the attenuator to avoid interaction.

The first transient generator inserts a preset voltage into the high voltage D.C. line as a "step" by opening and closing the push button microswitch marked " $\Delta \mathrm{P}$ ". The voltage step is also fed to a connector marked "SYNC". The "SYNC" signal is for measurements of response time on safety circuits associated with the pile flux monitor.

The second transient generator consists of a motordriven helipot combination which supplies an output voltage that varies exponentially with time. The exponential covers two decades of voltage, 1.e. from 1.05 volts to 105 volts. The motor control box varies the motor speed and direction of rotation. The motor speed determines the period of the growth or decay of the exponential voltage. The direction of the motor rotation determines whether the exponential is growing or decaying. Any period between 1.5 seconds and 180 seconds can be generated. The motor control is a General Radio Model $1701 \mathrm{AE}$ and is shown in Figure 2.

The output of the motor-driven helipots only approximates an exponential curve; a graph of the voltage output for various shaft positions is shown in Figure 4. The deviation 


\section{$\mathrm{DP}-79$ \\ Page 9}

from an ideal exponential curve is about two per cent of the maximum value. The slight ripple in the response characteristic causes a fluctuation in the logarithmic derivative. Over about 90 per cent of the range of the helipots, the median of the fluctuating derivative is within 10 per cent of the constant logarithmic derivative of the "Ideal" curve. More complicated methods of curve compensation in the network are possible (1)(2), but the circuit that is used here is adequate for the purpose.

The voltages from the transient generators are fed to an attenuator. The resistor values shown in Figure 1 were sufficient to cover the current range from $10^{-13}$ amperes to $10^{-4}$ amperes. To get $10^{-13}$ and $10^{-12}$ amperes, the attenuator is set to $1013 \mathrm{ohms}$ and the exponential generator is run down unt1l the output voltage to the attenuator is 1.05 volts and 10.5 volts respectively. A voltmeter to read this voltage is shown in Figures 1 and 2 .

USE

To use the tester, the signal output is connected to the input of the pile flux monitor with a length of high quality $R G-11 / u$ coaxial cable. With the A.C. power on, the monitor and the tester should be allowed to warm for about an hour.

Using the motor control box, run the motor until the voltmeter needle rises to the top of the voltmeter and stops. Turn the motor off. Any current between $10^{-11}$ and 10-4 amperes may be put into the monitor micromicroammeter by selecting the correct attenuator resistor on the dial marked "P". For 10-13 and 10-12 amperes, the motor must be reversed and run until the voltmeter reads one per cent of its scale; then the 1013- and 1012-ohm resistors may be used.

To use the "step" generator for measuring response time of instruments, set the "P" attenuator to the desired resistance value with the voltmeter reading full scale. Connect the "Start" input of a time measuring instrument, such as a Hewlett Packard Model 522B Interval Timer, to the tester "SYNC" output. Connect the interval timer "STOP" input to the circuit point of interest in the pile controls. By pressing the " $\Delta \mathrm{P}$ " microswitch on the tester, the interval timer is started. When the pile control responds, the interval timer is stopped and the time delay can be read on the panel of the interval timer.

To calibrate a period circuit for positive periods, the motor is run so as to cause the voltmeter to drop to one per cent of full scale. The motor is stopped and the "Forward-Reverse" switch is set on "Forward". The attenuator 


\section{$\mathrm{DP}-79$

" $P$ " should be set to give the desired initial current. To begin with, the Variac speed control is set to about 3 or 4 . The motor switch is turned "ON" and a stopwatch is used to time the number of seconds required for the voltmeter needle to travel from 1 per cent to 100 per cent of full scale. The period is given by:

$$
\text { Period }=\frac{\text { Seconds to travel from } 1 \text { to } 100}{4.6} \text { seconds }
$$

The Variac speed control should be varied until the desired period is generated; the period indicated on the period meter may then be compared to that calculated above.

To generate negative periods, the voltmeter has to start from the 100 per cent position and "P" must be set to give an appropriate initial current.

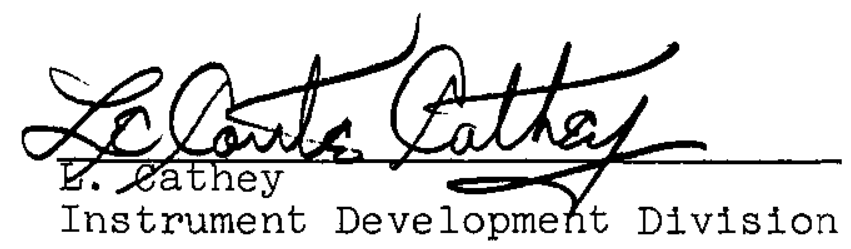




\section{BIBLIOGRAPHY}

1. Painter, N. H. Matching Resistance Curves by Means of Two Linear Ganged Potentiometers and A Three Terminal Resistance Network. Radiation Laboratory MIT RL-610 August 17, 1944.

2. Potentiometer Handbook. Technology Instrument Corporation, Acton, Mass., January 1954. 


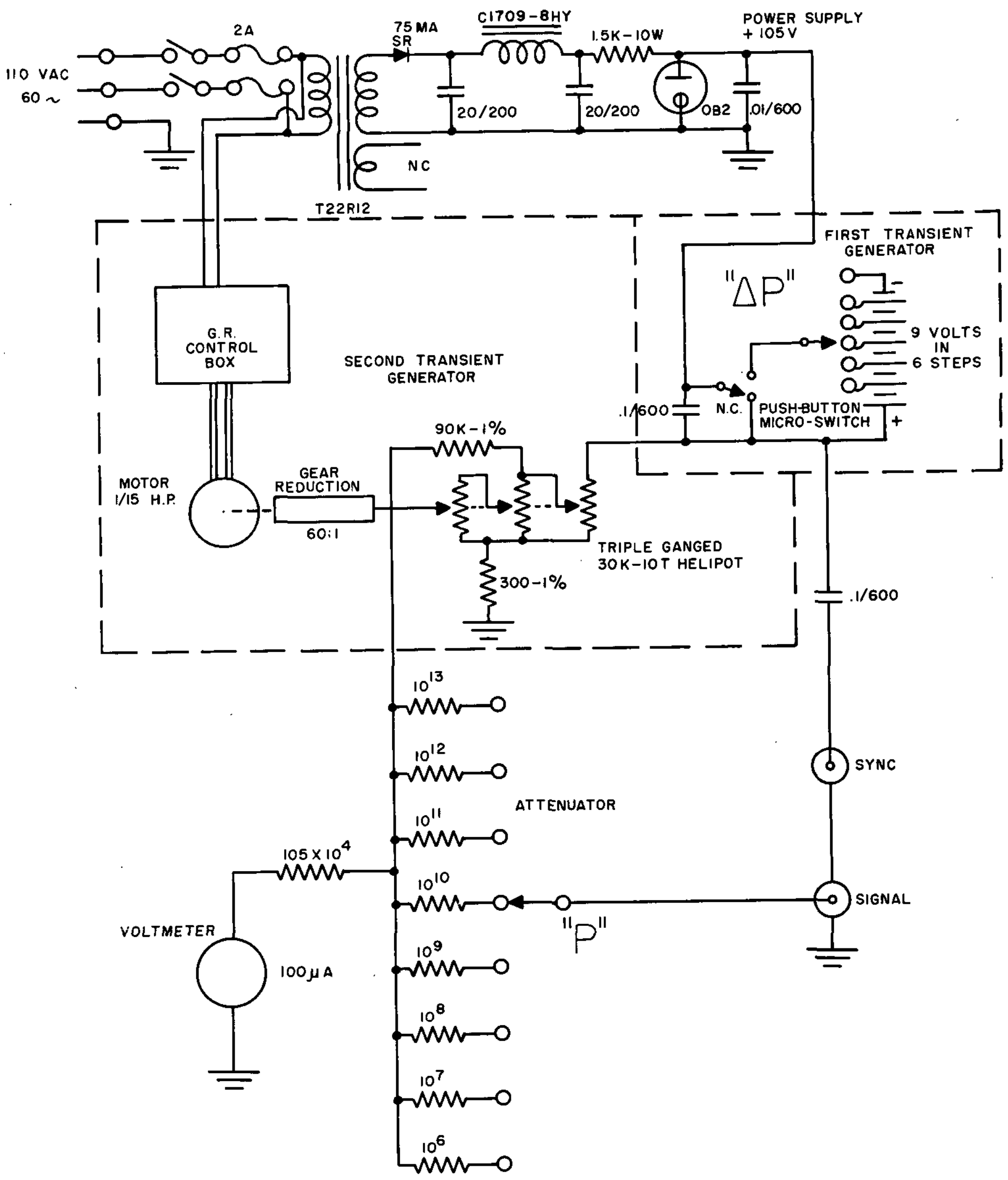


Figure 2

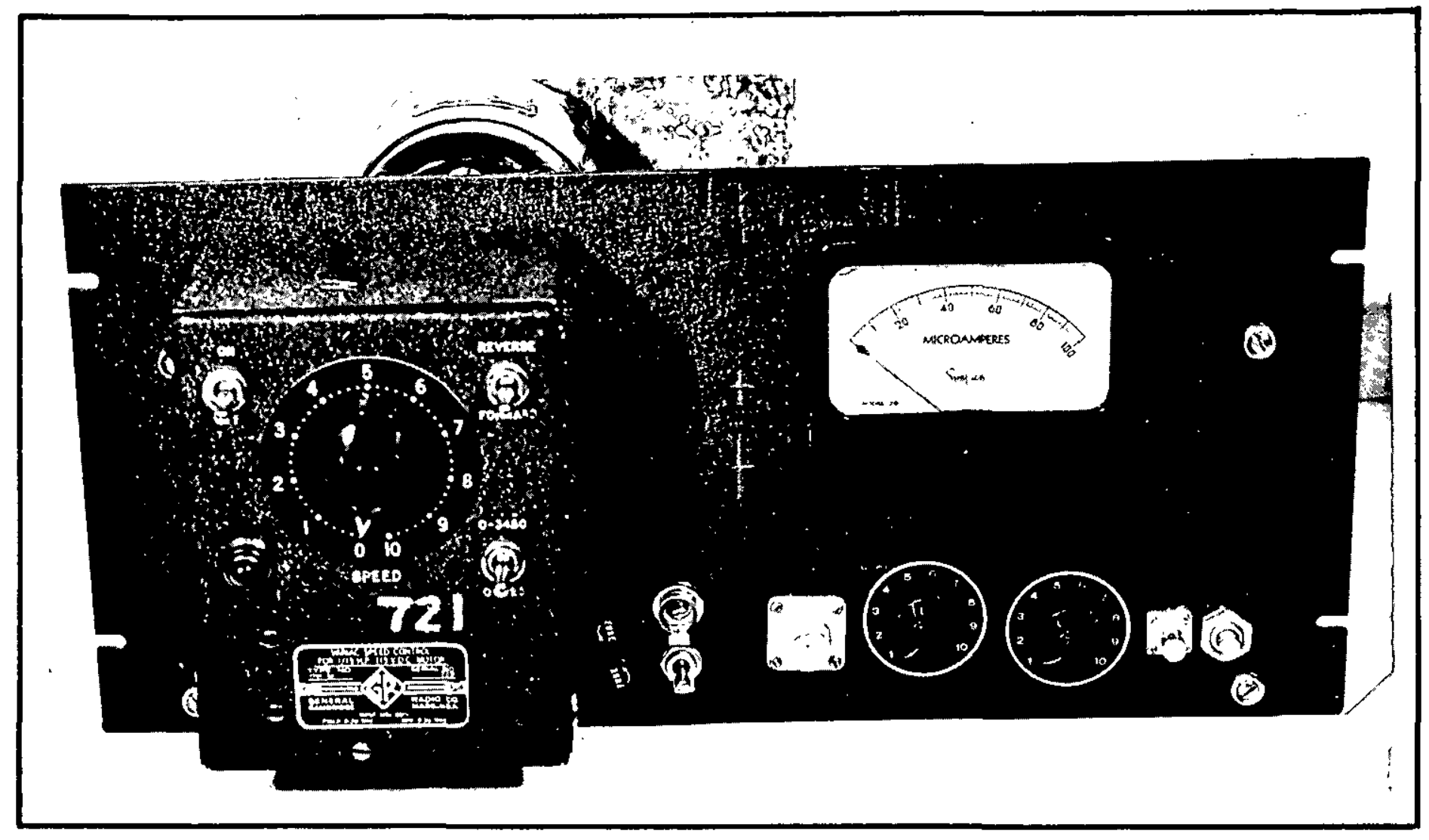

PHOTOGRAPH OF THE PANEL 
Figure 3

DP - 79

Page 14

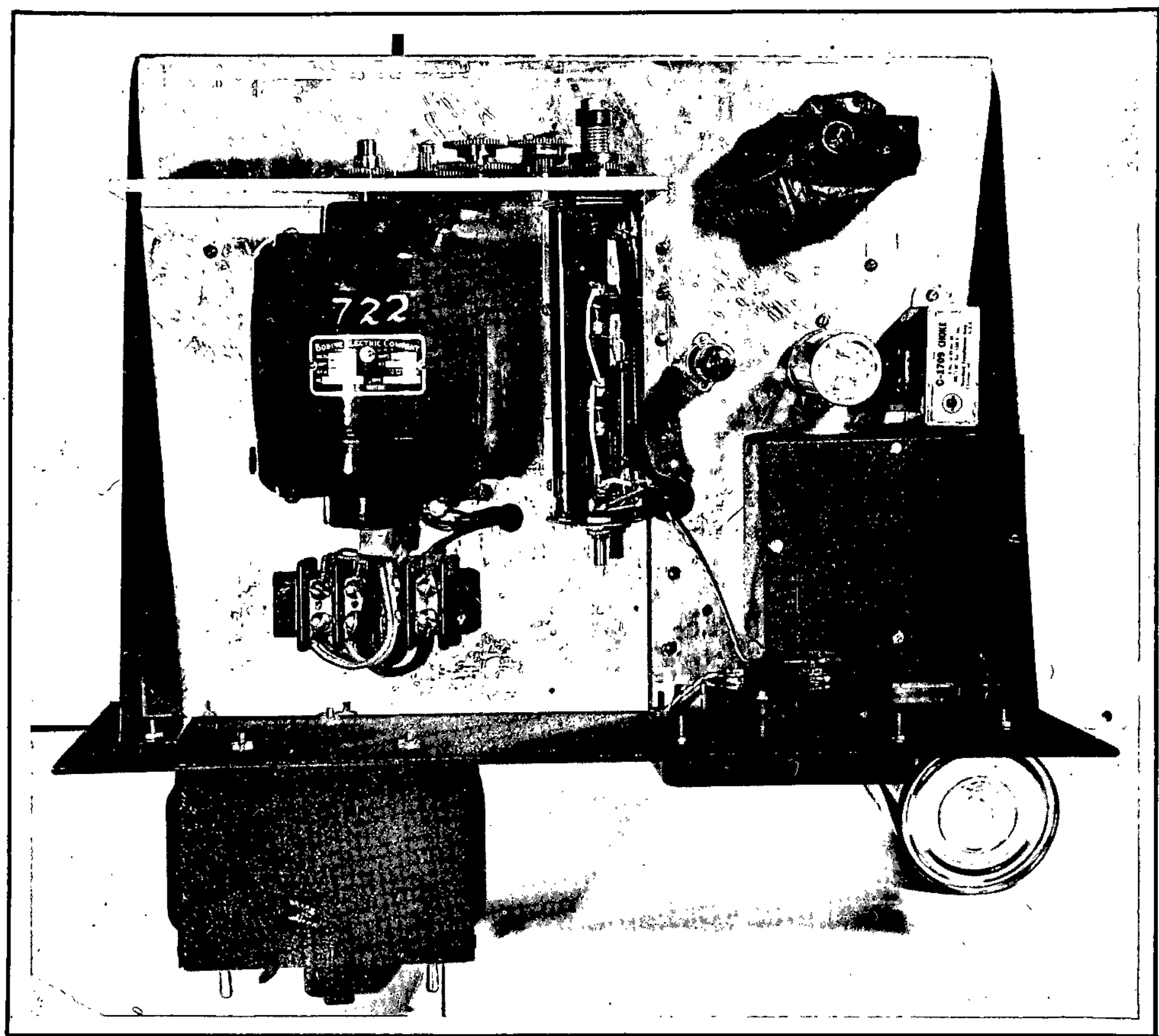

PHOTOGRAPH OF TOP OF CHASSIS 


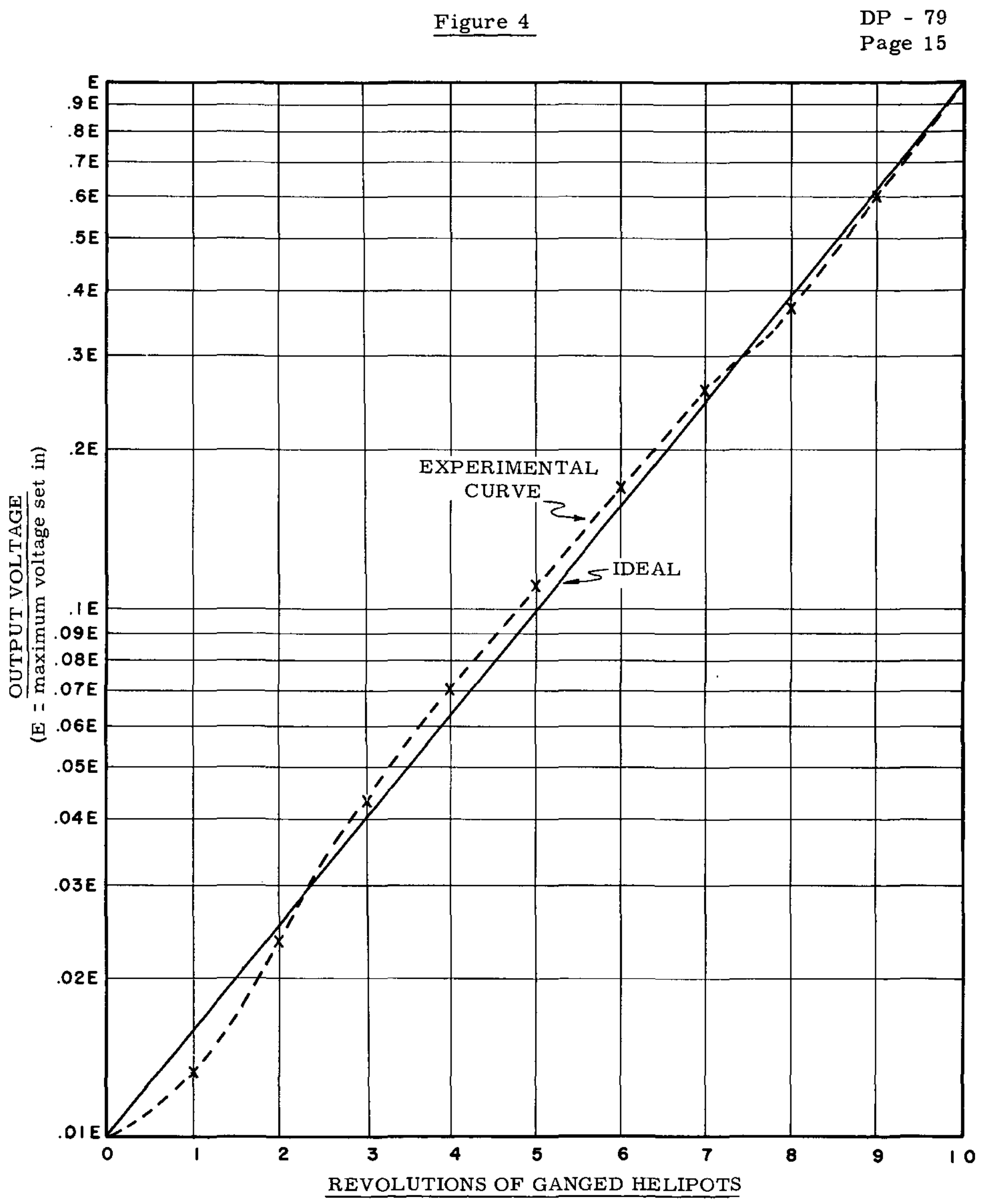

